\title{
Exteriorizaçấo, AlienaÇão e Formação Cultural no Capítulo VI da Fenomenologia do Espírito
}

\author{
João Emiliano Fortaleza de Aquino
}

\begin{abstract}
RESUMO: Nossa proposta é pensar a relaçăo entre a função sistemática da Fenomenologia do Espirito, no pensamento de Hegel, e as categorias de exteriorização e alienação, conforme o objeto e o método expositivo próprios dessa ciência filosófica (e da obra que a expóe). Dessa forma, apresentamos a hipótese de uma fundamental relação entre alienação e formação cultural no capítulo VI da Fenomenologia do Espírito. A demonstração de que a exposição dessa obra não trata diretamente de objetos, mas da experiência da consciência frente a esses objetos, se afasta de uma leitura que a toma como tematização de relaçốes sociais objetivas.
\end{abstract}

PALAVRAS-CHAVE: Exteriorização. Alienação. Formação Cultural. Hegel.

A Manfredo Araújo de Oliveira, que há várias gerações nos ensina a especificidade da Filosofia.

Neste artigo, visamos a tematizar os conceitos de exteriorização (Entäusserung) e alienação (Entfremdung) no capítulo "VI. O espírito", da Fenomenologia do Espírito, particularmente no subcapítulo "B. O espírito alienado de si mesmo. A formação cultural". ${ }^{2}$ Considerando esse problema, pretendemos, neste trabalho: (I) discutir qual a questão filosófica específica da Fenomenologia do Espírito e sua função sistemática; e (II) argumentar que

\footnotetext{
${ }^{1}$ Doutor em Filosofia pela Pontifícia Universidade Católica de São Paulo, Professor Associado da Universidade Estadual do Ceará.

${ }^{2}$ Cf. HEGEL (1992b; 1970d). Na tradução brasileira, P. Meneses optou por traduzir Entäusserung por "extrusão" e Enfremdung por "alienação". Neste último caso, sigo-o em sua opção, que é a mesma de P.-J. Labarrière (1979) e de J. H. dos Santos (1993); e, como estes últimos, opto - sendo esta uma diferença năo-problemática com a opção de P. Meneses - por "exteriorizaçáo" (distancio-me, assim, da opção por "alienação" para Entäusserung, como o fez a primeira tradução francesa, de J. Hyppolite (1999)). Quanto à Bildung, que Meneses traduz por "cultura", traduzo-a aqui por "formaçáo cultural", para reforçar a ideia de processo ativo, presente no termo alemão, e para diferenciar de Kultur, "cultura", resultado já de certo processo formativo. Encontra-se, nesta opção, algo que me parece central a este texto hegeliano: a relaçáo entre as experiências de formação (Bildung) e de alienação (Entfremdung). Feitas essas observaçóes preliminares, modificarei, conforme a elas, as citaçóes que neste artigo farei de textos de Hegel, sem precisar mais, a cada vez, indicar a modificação.
} 
exteriorização e alienação não se constituem aí em categorias sociais objetivas (i.e., como determinaçóes do espírito objetivo), mas, de fato, conforme o método próprio à apresentação da obra, em figuras da consciência; enquanto tais, conformam no percurso da consciência rumo à ciência as determinações fundamentais de uma formação cultural (Bildung), que, na economia interna da Fenomenologia do Espirito, consiste na condução necessária da consciência ao ponto de vista filosófico, i.e., ao saber absoluto.

\section{CONSIDERAÇÓES GERAIS SOBRE O LUGAR SISTEMÁTICO DA FENOMENOLOGIA DO ESPÍRITO}

$\mathrm{Na}$ Fenomenologia do Espirito, Hegel toma como objeto de tematização a consciência - forma imediata de aparição do espírito, fenômeno do espírito -, pretendendo mostrar que, em sua experiência, a consciência chega ao saber de si enquanto espírito, ultrapassando assim o horizonte da filosofia moderna que, segundo avalia o próprio Hegel, toma como horizonte último-primeiro de suas consideraçôes a consciência finita abstraída de suas relaçôes históricas, sociais, culturais - portanto, na terminologia hegeliana, "espirituais". ${ }^{3}$ Hegel apresenta uma experiência da consciência em que esta tem sua verdade e seu fundamento para aquém de sua imediatidade, num aquém que, no entanto, dela não se afasta, mas lhe substancia, ao demonstrar-se como o verdadeiro sujeito de sua experiência, precisamente na medida em que a consciência é o ser-aí do espírito. O que nessa exposição Hegel quer é mostrar a necessidade do ponto de vista filosófico em que a consciência, sabendo-se existência imediata do espírito, sabe também que o mundo que ela experimenta em e por suas figuras constitui um só com ela, de modo que o momento último dessa experiência da consciência é o da figura do saber absoluto, na qual se supera o ponto de vista da consciência, que separa sujeito e objeto, pensamento e ser. É essa, por conseguinte, a figura na qual a consciência em sua experiência concebe a identidade ser e pensamento, ponto de chegada ao elemento simples

\footnotetext{
3 "Para Hegel, o pensamento moderno, que se explicitou em sua plenitude na filosofia transcendental de Kant e Fichte, é uma nova forma de metafísica do entendimento, pois se trata de uma metafísica da subjetividade, i.é, tudo pensa a partir da contraposiçâo entre sujeito e objeto. A subjetividade se faz, assim, a fonte de sentido capaz de determinar tudo o que a ela se contrapóe" (OLIVEIRA, 1993, p. 182-183). Ainda segundo Oliveira (1989, p. 41), é o confronto com essa posição moderna que essencialmente constitui a própria posição hegeliana: "Hegel questiona esta contraposição entre subjetividade e objetividade e pretende pensar as categorias como adequadas, como expressão da identidade sujeito e objeto, que ele considera o princípio da especulação".
} 
da Ciência e, em consequência, ponto de transição entre a Fenomenologia do Espirito e a Ciência da Lógica. ${ }^{4}$

O capítulo "VI. O espírito" se situa na chamada segunda parte da Fenomenologia do Espírito. Se a "primeira parte" dessa obra, composta por cinco capítulos, se constitui das experiências da consciência em suas figuras subjetivas, experiências, pois, em que a consciência tem por objeto realidades exteriores sensíveis-naturais, esta "segunda parte" contém, como sempre é o caso da exposição nesta obra, a experiência da consciência, de fato, porém, em suas figuras do espírito. Esse sexto capítulo situa-se entre os cinco primeiros capítulos da obra e os dois últimos - "VII. Religião" e "VIII. O Saber Absoluto"; situa-se, portanto, entre os capítulos em que a consciência se constitui em figuras experienciais nas quais é a própria consciência que está sendo experimentada - seja como consciência sensível, como consciência perceptiva, como consciência intelectiva (entendimento), como consciência de si ou como consciência que se sabe razão - e aqueles em que a consciência se experimenta em figuras nas quais se busca a superação da separação entre ela e o objeto, primeiramente nas diversas formas de consciência religiosa (religiáo natural, religião da arte, religião revelada), depois na consciência filosófica do saber absoluto. Assim, nessas figuras do capítulo sexto da Fenomenologia do Espírito, a consciência ainda tem o seu objeto diante de si (é precisamente isto o que evoca a palavra alemá para objeto: Gegenstand, "parado diante de"), contudo, não são mais objetos exteriores sensiveis-naturais cujos saberes conduzem a consciência a uma experiência consigo, porém, são objetos espirituais cujos saberes, ainda que também e certamente numa experiência da consciência consigo mesma, se dão no interior de relaçôes ético-genéricas, histórico-sociais, culturais.

O que temos em todo esse trajeto da experiência é a crítica de Hegel à concepção fixa, imóvel, da consciência, tal como ele enxerga na filosofia transcendental, a qual, segundo avalia, retira a consciência das relaçóes nas quais e pelas quais ela se constitui, relaçóes estabelecidas tanto com seus

\footnotetext{
${ }^{4}$ Sobre essa função sistemática da Fenomenologia do Espírito, assim se expressa Lima Vaz (1999, p. 381): "Hegel se impóe então como tarefa preliminar à construçâo do Sistema mostrar, num discurso articulado segundo uma sequência histórico-dialética, como a formação da consciência para a ciência - para o saber do Sistema - termina necessariamente no Saber absoluto que assinala a suprassunção do fenomenológico no lógico ou da oposiçáa da consciência na emergência do Absoluto, manifestando-se na posição do ser puramente inteligível, ponto de partida do discurso sistemático. O saber absoluto designa, assim, a passagem da subjetividade da consciência para a objetividade da Idéia, onde se dará a demonstração cabal, no Sistema, da proposição o Absoluto é espirito. Descrever, pois, o caminho da consciência para o Saber absoluto, eis o alvo visado pela Fenomenologia [...]".
} 
objetos (representados numa existência separada), quanto com outras consciências e, mais ainda, com uma existência do espírito que antecede histórica e logicamente as relaçóes entre consciências finitas, pondo-se assim em relação reflexo-especular com seu verdadeiro, pois infinito, fundamento imanente. Que a consciência, em sua existência finita, não se saiba o ser-aí do espírito, é precisamente o que é superado em sua experiência, na qual aquela vai sempre além de si, além de suas figuras determinadas, isoladas, através de uma autonegaçáo imanente que a conduz, progressivamente, à sua verdade.

Nesse trajeto, a consciência se constitui em figuras cujos polos são os momentos de saber e de verdade. Salienta Hegel, na Introdução à Fenomenologia do Espirito:

[...] a consciência distingue algo de si e ao mesmo tempo se relaciona com ele; ou, exprimindo de outro modo, ele é algo para a consciência. $\mathrm{O}$ aspecto determinado deste relacionar-se - ou do ser de algo para a consciência - é o saber. Nós, porém, distinguimos desse ser para um outro o ser-em-si; o que é relacionado com o saber também se distingue dele e se póe como algo-que-é [seiend], mesmo fora dessa relação: o lado desse em si chama-se verdade. (HEGEL, 1992a, p. 69; 1970d, p. 76).

Porquanto finitas, logo, contraditórias, essas figuras se sucedem impulsionadas por uma negatividade que lhes é interna, negatividade esta que se apresenta na negação imanente do saber pela verdade. A consciência, nesse texto hegeliano, é sempre uma figura, uma determinada configuração dos momentos de saber e verdade. Não é jamais uma substância (ainda que finita), como a res cogitans cartesiana; é sempre uma determinada Gestalt, "figura", "configuração", "conformação", caracterizada nâo apenas por sua relação com o objeto externo, o que apenas significaria uma posição análoga à do empirismo, mas por essa relação entre saber e verdade no interior da própria consciência, relação esta que lhe permite exteriorizar-se em seu objeto e cujo desacordo a conduz interiormente a uma nova figura em sua estrutura bipolar. Assim, a consciência é sempre consciência de um objeto e, por isso, constitui-se de um momento objetivo, no seu próprio interior, momento em que e pelo qual o objeto é para a consciência - não exteriormente, insisto -, mas como momento interno constitutivo da própria consciência (trata-se do momento do saber). Contudo, como a consciência não se esgota nessa relação com aquilo do qual se distingue (ou seja, o objeto exterior), embora enquanto consciência se constitua necessariamente desta relação, ela é também um em- 
si (o momento da verdade) que toma como objeto interior o saber, i.é, sua própria relação com o objeto exterior. ${ }^{5}$ Em outras palavras, a consciência faz do próprio saber - momento interno seu constituído em e pela sua relação com o objeto externo - um objeto interno; é tal relação com o saber no interior da própria consciência que Hegel chama de momento de verdade, o qual examina o saber do objeto (fazendo deste próprio saber seu objeto), encontra suas contradiçóes e o impulsiona à própria superação.

Ora, mas de que se constitui esse em si, esse momento de verdade? Para Hegel, o que o constitui é o que constitui igualmente a própria consciência e seu momento de saber. A verdade do saber é sempre aquela verdade determinada daquele saber determinado, pois, do ponto de vista da experiência da consciência, esta é sempre a consciência determinada daquele objeto determinado e, portanto, se constitui sempre como aquele saber; assim, o momento da verdade não poderia ser constituído senão nessa mesma relação reflexiva determinada. Desse modo, Hegel pretende garantir um movimento imanente à consciência, no qual ela se supera progressivamente a si mesma. Logo, esse movimento imanente de superação da consciência é uma negação da consciência por ela mesma, o que a capacita a ir para além de sua configuração presente, em vista de outra configuração; trata-se da negação deste saber por esta sua verdade, o que resulta no que Hegel chama de "negaçáo determinada". ${ }^{6}$ Como o momento da verdade, no interior da consciência, não é ele mesmo fixo, mas é sempre a verdade de um determinado saber que a consciência tem do objeto - sendo, pois, a verdade desse saber -, a negaçáo que ela lhe opõe é uma negação imanente e determinada. Todavia, do ponto de vista de uma fenomenologia do espírito - e a experiência da consciência revela-se, ao final, como uma fenomenologia do espírito, como uma ciência do ser-aí (consciência) do espírito -, esse movimento imanente da consciência, essa dialética de saber e verdade interna à consciência, tem como verdadeiro

\footnotetext{
${ }^{5}$ Não há dúvida de que essa bipolaridade da consciência na Fenomenologia é devedora do desenvolvimento da filosofia transcendental, particularmente da natureza reflexiva da subjetividade finita, tal como a encontramos em Kant (sobretudo na terceira Crítica) e em Fichte.

6 "Essa apresentação da Fenomenologia do Espírito, em seu início, parte da insurgência de uma questão, tipicamente moderna, de ordem metodológica, que é a medida, ou melhor, a realidade do conhecimento. Para Hegel, essa questão traz a contradição entre saber e verdade e com ela a dicotomia entre o subjetivo e o objetivo. Assim, a consciência quer que sua certeza - subjetiva e interior -, tenha verdade - objetiva e exterior. A princípio, para solucionar o problema, Hegel articula na consciência esses dois momentos, com os quais ela se diferencia e se relaciona reciprocamente, e expressa um como 'algo para a consciência', que é o saber, e o outro como 'ser de alguma coisa para a consciência', que é o objeto. Com isso, tenta solapar as bases do impasse acerca da unidade de medida do saber, imposta pela filosofia moderna, expondo sua intenção de uma justificaçăo imanente da medida [...]" (BARBOSA, 2010, p. 89).
} 
sujeito o espírito e, nesse sentido, tem como pressuposto imediato para a consciência seu próprio desenvolvimento histórico-temporal (que é, afinal de contas, manifestação efetiva temporal do absoluto).

Assim, enquanto configuraçôes/conformaçóes da consciência constituídas pelos momentos internos de saber e verdade, as figuras da consciência que Hegel nos apresenta, nessa ciência da experiência da consciência/fenomenologia do espírito, não são de modo algum categorias objetivas da filosofia real (natureza e espírito). ${ }^{7}$ E não o são nem mesmo quando - como precisamente ocorre no Capítulo VI - se constituem em figuras da consciência em sua experiência de si mesma no espírito, embora tais conteúdos objetivos componham, justamente como pressupostos, essa experiência da consciência. Tal relação da experiência da consciência com os conteúdos objetivos do mundo do espírito, em sua totalidade, é justamente uma das coisas que distinguem a posição hegeliana apresentada na Fenomenologia do Espírito da posição da moderna filosofia da subjetividade. Se não se trata, para Hegel, de tematizar diretamente nessa obra conteúdos objetivos da filosofia real, tampouco é o caso de tomar a experiência da consciência numa abstração desses mesmos conteúdos. Portanto, enfatiza Hegel (1995; 1970c), no $₫ 25$

\footnotetext{
${ }^{7}$ Refiro-me aqui à "grande" Fenomenologia do Espirito, publicada em 1807, e não à "Fenomenologia do Espírito", segunda seção (após a "Antropologia" e antes da "Psicologia") do espírito subjetivo, primeira seção da Filosofia do Espírito, que constitui a terceira parte da Enciclopédia das ciências filosóficas. Nessa retomada enciclopédica da experiência da consciência, Hegel a apresenta em apenas três grandes figuras (consciência, autoconsciência e razão), eliminando as figuras do espírito, da religião e do saber absoluto. A Fenomenologia do Espirito de 1807 deveria articular-se com a Ciência da Lógica, segundo salientam o Prefácio ao Sistema (publicado junto à Fenomenologia do Espírito, quando esta é apresentada como Primeira Parte do Sistema) e o Prefácio à Ciência da Lógica (1812); a esta última, deveriam seguir então as ciências (ou a filosofia) do real. Segundo a Filosofia Real (1805/06) - que, pela data, sugere o que, no período em que escreve a Fenomenologia do Espirito, entendia Hegel por "filosofia real" - esta se comporia de filosofia da natureza e filosofia do espírito, consistindo esta última em: I. Conceito de espírito, II. espírito real e III. Constituição; portanto, resguardadas as diferenças com os teores da Enciclopédia, a filosofia real a suceder a Ciência da Lógica conteria o que, na Enciclopédia, está focalizado na "Psicologia" (I) e no espírito Objetivo (II e III). (Cf. HEGEL, 1984). Em vista disso, a relaçấo entre a grande e a pequena Fenomenologia é uma questão sempre aberta, no debate hegeliano, permanecendo problemático o lugar que, no sistema, cabe à obra de 1807 , se se tem em vista o acabamento sistemático da filosofia apresentado pela Enciclopédia de 1817, no qual ela se liga náo mais à Ciência da Lógica (ou à "pequena lógica", primeiro tomo da Enciclopédia), mas, como já lembrado, à "Psicologia" (ciência filosófica que, culminando o espírito subjetivo, nos apresenta o conceito de espírito, que, como sujeito, se objetiva em seguida no espírito objetivo). Para uma discussão mais ampla sobre esse problema, cf. POEGGELER (1985); para o problema, também aí presente, da natureza da Fenomenologia do Espírito como introdução à ciência e, ao mesmo tempo, uma ciência filosófica específica, cf. BARBOSA (2010).
} 
da Enciclopédia das ciências filosóficas, referindo-se exatamente à Fenomenologia do Espirito de 1807:

[...] não se podia ter ficado no formal da simples consciência: pois o ponto de vista [Standpunkt] do saber filosófico [isto é, o saber absoluto] é em si ao mesmo tempo o mais pleno de teor [gehaltvollste] e o mais concreto; por conseguinte, ao desprender-se como resultado, ele pressupunha [setze ... voraus] também as figuras concretas da consciência, como por exemplo, as figuras da moral, da ética, da arte, da religião. O desenvolvimento do teor [Gehalt], dos objetos [que são] partes próprias da ciência filosófica, incide [cai, fällt], pois, ao mesmo tempo, nesse desenvolvimento da consciência que inicialmente parecia restrito apenas ao formal. Esse desenvolvimento [do teor] deve, por assim dizer, avançar por trás [da experiência] da consciência, na medida em que o conteúdo [Inhalt] se relaciona à consciência como Em-si. A exposiçáo torna-se, por isso, mais complicada, e o que pertence às partes concretas [do sistema, isto é, a filosofia da natureza e a filosofia do espirito] já recai [cai, fällt] nessa introdução [à Ciência [que é a Fenomenologia do Espirito]].

Em outras palavras, o problema próprio da Fenomenologia do Espirito é a consciência (enquanto ser-aí do espírito), cuja experiência é apresentada nessa obra em seu aspecto formal, isto é, como consciência tout court. Contudo, seu desenvolvimento, na medida em que, por conta da crítica que Hegel busca realizar da filosofia da subjetividade, não podia ser tomada apenas em sua formalidade, pressupóe - mas este é um pressuposto que, apenas indicado, não é ele mesmo diretamente tematizado - o desenvolvimento objetivo $\mathrm{e}$ concreto do espírito e seus conteúdos. Quando Hegel usa o verbo "pressupor" (voraussetzen), não o faz ingenuamente: ele quer dizer precisamente de algo que subsiste anterior (vor) e exteriormente (aus), de modo que o desenvolvimento do teor do espírito só aparece como pressuposto, que age "por trás (hinter) da experiência da consciência”. Esse conteúdo - porque o ponto de vista de Hegel é o de que a consciência náo pode ser pensada como pura forma, abstraída daquilo que é seu verdadeiro fundamento: o espírito - termina por cair, recair, incidir nas figuras da consciência na Fenomenologia do Espírito, mas, somente, segundo a exposiçáo própria dessa obra, enquanto a consciência em sua experiência se lhe refere como a um objeto externo e assim o faz, internamente, em seu saber. Consequentemente, o que é tematizado na Fenomenologia do Espirito não é o próprio conteúdo e os teores concretos do espírito, este mesmo o verdadeiro fundamento da experiência da consciência, mas, de fato,sua imediatidade fenomênica: a consciência. 
Esse método da Fenomenologia do Espirito é inseparável da sua relação com o todo do Sistema e, particularmente, com a Ciência da Lógica. Essa ligação está em que o desenvolvimento da consciência, na medida em que esta é o fenômeno ou o ser-aí do espírito, resulta - na figura do saber absoluto - no saber da identidade entre o pensar e o ser, identidade esta que somente se pode apresentar nas determinaçóes do próprio pensar, enquanto elas se desenvolvem e se expóem como determinaçóes do que efetivamente é. ${ }^{8}$ Quer dizer, o termo da experiência da consciência é o saber-se a si mesma como espírito, um saber que, numa ascese dialética, eleva a consciência ao ponto de vista filosófico, absoluto. A consciência, afirma Hegel (s/d, p. 5), no Prefácio à primeira edição (1812) de A ciência da Lógica,

[...] enquanto é o espírito manifestando-se, que, no seu caminhar, se libera de sua imediatidade e concreçáo, alcança o nível do saber puro que tem por objeto estas essencialidades propriamente puras, tais como são em e por si. São puros pensamentos, o espírito que pensa sua essência. Seu automovimento é sua vida espiritual, ele é isto pelo quê a ciência se constitui e isto do quê ela é a apresentação.

A essa passagem, Hegel acrescenta, no parágrafo seguinte: "Por aqui se acha indicada a relação da ciência que eu nomeio Fenomenologia do Espírito com a Lógica” (p. 5). ${ }^{9}$

\footnotetext{
${ }^{8}$ Que as determinaçóes lógicas sejam apresentadas como determinaçōes do pensamento, na medida em que estes são determinaçóes do real, esta é uma exigência posta por Hegel a si pela necessidade de evitar o paralelismo em que se dá, em Spinoza, a identidade ser e pensar (paralelismo entre os atributos de pensamento e extensão). Trata-se, para Hegel, de expor/apresentar a identidade entre o pensamento e o ser por um desenvolvimento negativo-imanente de exteriorização e efetivação do próprio pensar. Que o sistema possa se fundar no lógico e, ainda assim, afirmar a identidade pensar e ser, é porque o lógico se exterioriza na natureza e no espírito, confirmando-se, no elemento do saber filosófico, como o sujeito dessa exteriorização que a si mesmo "retorna" (reflete) na forma da especulação.

${ }^{9}$ Cf. também o "Prefácio" ao Sistema, publicado junto à Fenomenologia do Espírito (HEGEL, 1992a, p. 40-41; 1970d, p. 39): "Quando a substância tiver revelado isso completamente [ser essencialmente sujeito], o espírito terá tornado seu ser-aí [a consciência] igual à sua essência [o próprio espírito]: [entáo] torna-se objeto para si mesmo tal como ele é; e foi superado o elemento abstrato da imediatez e da separação entre o saber e a verdade. O ser está absolutamente mediatizado: é conteúdo substancial que também, imediatamente, é propriedade do Eu; tem a forma do $\mathrm{Si}$, ou seja, é conceito. [ $\mathbf{g}$ ] Neste ponto se encerra a Fenomenologia do Espirito. O que o espírito nela prepara para si [in ihr sich bereitet] é o elemento do saber. Agora se expandem nesse elemento os momentos do espírito na forma da simplicidade, que sabe seu objeto como igual a si mesma. Esses momentos já não incidem na oposição entre o ser e o saber, separadamente; mas ficam na simplicidade do saber [...]. Seu movimento, que nesse elemento [do conceito] se organiza em um todo, é a Lógica ou Filosofia Especulativa". (Tradução levemente modificada; colchetes em itálicos são meus, colchetes normais do tradutor).
} 


\section{BILDUNG E ENTFREMDUNG: FORMAÇÃo CULTURAL E ALIENAÇÃo}

Se a figura do saber absoluto é o resultado para o qual se dirige a experiência da consciência, o momento que particularmente nos interessa mais uma vez, o capítulo "VI. O espírito" - situa-se justo no momento em que a consciência experimenta suas próprias figuras enquanto figuras do espirito. Não nos enganemos a este respeito: aqui, Hegel não abandona as figuras experienciais da consciência para tematizar as categorias ou as determinaçóes do espírito objetivo, das conformaçóes histórico-sociais concretas, embora as tenha como pressupostos. Aqui encontramos propriamente, segundo o próprio Hegel, a "consciência do mundo do espírito finito".

Essa expressão se encontra num manuscrito dos cursos de Hegel em Nuremberg, nos anos 1808-1809 (publicado por Hoffmeister, nos Nürnberger Schriften). ${ }^{10}$ De acordo com esse manuscrito, Hegel pretendia ministrar um curso sobre a Pneumatologia ou Ciência do Espírito; essa Pneumatologia deveria compreender a Fenomenologia (teoria da consciência) e a Psicologia. Tal teoria da consciência corresponde à Fenomenologia do Espirito inteira (donde se demonstra que, nesse período, o filósofo ainda mantinha o ponto de vista sistemático indicado pelo Prefácio ao Sistema de 1807, confirmado pelo Prefácio à Ciência da Lógica, de 1812, e não ainda o da Enciclopédia), tendo três partes: "A. Consciência dos objetos abstratos. B. Consciência do mundo do espírito finito. C. Consciência do espírito absoluto”. A parte A seria dividida em Consciência, Consciência de si e Razão; a parte B corresponderia ao capítulo sexto da Fenomenologia do Espirito, sobre o espírito; e a parte C, aos capítulos sobre religião e saber absoluto.

Esse manuscrito, tal como Poeggeler o apresenta, é central para a presente interpretação da própria Fenomenologia do Espírito: os cinco primeiros capítulos tratam da "consciência dos objetos abstratos" e o capítulo sexto, sobre o espírito, constitui, de acordo com o próprio Hegel, uma exposição da, repito, "Consciência do mundo do espírito finito". Trata-se aí, como em toda a Fenomenologia, da consciência enquanto imediatidade do espírito; assim, fundamentalmente, náo é o próprio espírito finito, em sua objetividade concreta (espírito objetivo, segundo a terminologia da Enciclopédia), que aborda o sexto capítulo, mas a consciência do mundo do espírito finito, ou ainda, o espírito finito em seu saber na consciência.

${ }^{10}$ Descrevo, a seguir, conforme as indicaçóes de POEGGELER (1985, p. 168-169). 
Neste ponto, é preciso observar que a transição das primeiras figuras da consciência às figuras do espírito é objeto do debate entre os estudiosos de Hegel. Conforme interpreta O. Poeggeler, na introdução da segunda seção "Autoconsciência" -, e como fundamento das figuras do senhorio e da servidão (ou, ainda, da autonomia e da inautonomia da consciência), a apresentação filosófica do percurso fenomenológico expóe, já ali, o conceito do espírito; ${ }^{11}$ no sexto capítulo, Hegel dá continuidade justamente ao ponto a que já havia chegado, no capítulo da Autoconsciência: o conceito de espírito, no qual essência e aparência se correspondem. ${ }^{12}$ Também Pierre-Jean Labarrièrre (1987, p. 10) considera que somente na seção do espírito vamos encontrar figuras da consciência enquanto figuras históricas, ou melhor, figuras do espírito, ainda que "de alcance frequentemente limitado". É nessa seção que um primeiro grande movimento da exposição fenomenológica se concluiria: nela, o espírito reconcilia a consciência e a autoconsciência na história (espírito objetivo). Por isso mesmo, para ele, não haveria nesse capítulo uma simples retomada do conceito de espírito presente na seção da Autoconsciência (como o defende Poeggeler): se o conceito de espírito de que resulta a Autoconsciência se define na fórmula "Eu, que é Nós, Nós que é Eu”, o conceito de espírito a que chega e com que conclui a seção do espírito se apresenta como "[...] o ser-aí do Eu expandindo-se em dualidade e que aí permanece igual a si" (HEGEL, 1992b, p. $142 ; 1970$ d, p. 494).${ }^{13}$ Assim, o capítulo do espírito ocupa um lugar central, como mediação ao conjunto da obra: é ele que, para Labarrière, mediaria a ascese da consciência ao ponto de vista do saber absoluto, e isso justamente porque o conceito de espírito que ele produz em seu final já não é mais o

\footnotetext{
11 "Para nós, portanto, já está presente o conceito do espírito. Para a consciência, o que vem-a-ser mais adiante, é a experiência do que é este espírito: essa substância absoluta que na perfeita liberdade e independência de sua oposiçẫo - a saber, das diversas consciências-de-si para si essentes - é a unidade das mesmas: Eu, que é nós, nós que é Eu" (HEGEL, 1992a, p. 125; 1970d, p. 145).

${ }^{12}$ Para demonstrar filologicamente essa interpretação, Poeggeler lembra que, no sumário da primeira edição da Fenomenologia do Espírito, Hegel distingue três seçóes: A. Consciência; B. Consciência de Si e C., uma seção que permanece sem título e à qual correspondem todas as partes seguintes da Fenomenologia do Espirito: razão, espírito, religiāo, saber absoluto. Esta terceira parte, mais ampla, constituiria um só desenvolvimento do conceito de espírito, no qual resulta o desenvolvimento da seçăo Autoconsciência (POEGELLER, 1985, p. 184 ss).

${ }^{13}$ Conforme a interpretação de Labarrière (1987), na primeira definição, o espírito seria a substância que dá unidade à diversidade e oposiçáo existentes entre as diversas autoconsciências; em outras palavras, o espírito é a unidade ex post pelas autoconsciências que se distinguem. Na segunda definição, o espírito é, enquanto sujeito, a unidade ante post que se póe e se explica nas distintas autoconsciências. Segundo Labarrière (1987, p. 30-31), a primeira definição privilegiaria uma "[...] acomodação mútua e exterior dos termos", enquanto a segunda portaria "[...] a revelação de sua unidade originária na identidade de sua reduplicação interior".
} 
espírito finito, como o produzido pela Autoconsciência, mas o espírito infinito absoluto, objeto da religiáo e do saber absoluto.

De qualquer modo, para uma interpretação da natureza das figuras do espírito que Hegel expóe, no sexto capítulo, não deixa de ser importante a distinção, posta mais uma vez quando da apresentação do conceito de espírito na introdução ao quarto capítulo, entre o "para nós" da consciência filosófica (unicamente para quem se apresenta aí o conceito de espírito) e o "para a consciência", para quem, imersa na experiência, "vem-a-ser a experiência do que é esse espírito". Se à consciência filosófica o espírito já se mostra conceitualmente, para a própria consciência, contudo, o que ainda está por vir é a experiência do que é o espirito. Pela ligação entre o conceito de espírito do quarto capítulo e as figuras do espírito do sexto capítulo (tal como é sugerida, com enfoques distintos, tanto por Poeggeler quanto por Labarrière), é crucial, para a interpretação da natureza das figuras do espírito, a indicação do próprio Hegel de que, ao conceito de espírito que se oferece à consciência filosófica, segue a experiência do espirito pela consciência finita; em outras palavras, o que segue não é uma exposição conceitual do espírito, mas a exposição conceitual da experiência que a consciência faz "do que é o espírito". Assim, as figuras do espírito se constituem de figuras da consciência e encontram sua especificidade, antes de tudo, em que a consciência experimenta, como figuras suas, aquilo que é o seu próprio fundamento e, portanto, verdadeiro pressuposto de suas anteriores figuras.

Por consequência, nesse momento, a consciência abstrata, cuja experiência também abstrata Hegel aborda nos momentos anteriores da exposição fenomenológica (conforme aos Nürnberger Schriften, a seção "A. Consciência dos objetos abstratos"), sabe então que suas figuras anteriores nada mais eram do que abstraçóes do verdadeiro existente: o espírito. Se, no manuscrito de Nuremberg acima referido, Hegel chama as figuras da consciência, da autoconsciência e da razão de "consciência dos objetos abstratos", já na Fenomenologia do Espirito diz que as figuras que aparecem no capítulo VI são "espíritos reais", "efetividades propriamente ditas", pois são, "[...] em vez de figuras apenas [nur] da consciência, figuras de um mundo" (HEGEL, 1992b, p. 9; 1970d, p. 326). Não sendo "apenas" da consciência, mas também "de um mundo", as figuras do espírito continuam ainda a ser figuras da consciência, num nível superior de sua experiência, não se tratando aqui, pois, de uma saída da esfera consciencial da experiência para uma esfera agora objetiva e histórica da experiência do próprio espírito. Por isso mesmo, 
nos manuscritos publicados por Hoffmeister, Hegel nomeia a seção que corresponde aos conteúdos do capítulo VI da Fenomenologia do Espírito de "B. Consciência do mundo do espírito finito": trata-se ainda, pois, da consciência e não do próprio espírito finito.

É nesse ponto da experiência fenomenológica que aparece no texto hegeliano o problema da Bildung, "formação cultural". Com as figuras da Bildung, Hegel pretende justamente tematizar a experiência que o espírito tem em si e consigo mesmo com a exteriorização (Entäusserung) e a alienação (Entfremdung). Trata-se de uma experiência na qual a própria formação cultural, que implica uma saída de si em direção à exteriorização, é elemento objetivo, efetivo, porém, justamente assim, rígido e estranho face à autoconsciência. Isto é, o processo de formação cultural é definido por Hegel como "o espírito alienado de si mesmo", donde, pois, a Bildung, a Entäusserung e a Enfremdung se copertencerem e se constituírem reciprocamente. $O$ que centralmente caracteriza a experiência do espírito enquanto formação cultural e alienação é que, nesse caso, o espírito se experimenta em figuras da consciência para as quais a natureza efetiva, objetiva e, portanto, exterior do mundo espiritual se lhe apresenta como alienada (ou ainda, estranha). O que propriamente constitui a experiência da consciência nesse processo de formação cultural do espírito é que, nele, o espírito se apresenta para si mesmo numa efetividade rígida, enquanto exterioridade de si mesmo. Essa efetividade rígida, exterior, negação da consciência de si, é um mundo espiritual, histórico, social; é um mundo da efetivação, da exteriorização da própria autoconsciência, que nele, contudo, não se reconhece.

É preciso chamar atenção para dois aspectos desse quadro mais geral da relação entre Bildung, Entäusserung e Enfremdung. Primeiro: consiste em uma experiência da consciência em figuras da consciência as quais são também figuras do espírito; desse modo, a alienação é necessariamente consciencial, pois constitutiva dessas figuras experienciais da consciência. A consequência necessária disso é que a alienação ocorre nos termos de um náo-reconhecimento de si da autoconsciência na efetividade, na exterioridade; em outras palavras, o que constitui a alienação da autoconsciência em relação à exterioridade e à efetividade é o fato de que a autoconsciência nela não se reconheça. Que a alienaçáo se apresente na forma consciencial do não-reconbecimento de si da autoconsciência na efetividade e na exterioridade é uma consequência necessária do objeto e do método da Fenomenologia do Espírito, que não aborda 
experiências sociais efetivas, a não ser indiretamente, na medida em que elas - para dizer com Hegel - "recaem”, "incidem”, na experiência da consciência.

Segundo: é esse mesmo o motivo pelo qual a efetividade e a exterioridade ganham a marca negativa do não-reconhecimento da (ou pela) autoconsciência; são, por conseguinte, por ela experimentadas como alienação. É porque, na Fenomenologia do Espirito, se trata sempre da consciência - ainda quando as figuras da consciência são figuras do espírito - que a autoconsciência pode experimentar a efetividade exterior em sua existência própria como realidade exterior alienada, na qual ela náo se reconhece. Entretanto, não decorre desse quadro experiencial da consciência nenhuma relação necessária entre exteriorização e alienação; na economia interna da Fenomenologia do Espirito, ele somente diz respeito a um momento específico do espírito, momento que tematiza a formação cultural, concebida por Hegel como processo de cisão e separaçáo da autoconsciência de uma efetividade que se apresenta, à própria autoconsciência, como efetividade rígida, pois exterior.

Com efeito, não há, em Hegel, nem mesmo na Fenomenologia do Espirito, qualquer identidade necessária (lógico-conceitual) entre exteriorização (que conduz à efetivação) e alienação. ${ }^{14}$ Essa identidade se dá apenas nessa figura da seção do espírito na qual se tematiza a formação cultural, apresentada num quadro de cisão e separação que, devido ao objeto e ao método da Fenomenologia do Espírito, se interpóe entre a autoconsciência e a efetividade exterior. Se é certo sustentar que, nessa segunda parte da seção do espírito ("B. O espírito alienado de si mesmo. A formação cultural”), a efetividade exterior é alienada, porque é efetividade exterior, é necessário afirmar também, todavia, para náo se cair em imprecisóes e unilateralidades, que a efetividade exterior é alienada apenas porque num quadro de tematização da formação cultural numa exposição fenomenológica conforme às exigências postas pelo objeto e pelo método da Fenomenologia do Espírito.

Nessa exposição, Hegel tem distinta clareza da positividade valorativa da exteriorização, da efetivação e da própria alienação, na medida em que segundo a exposição da Fenomenologia - aquela última se inclui necessariamente

\footnotetext{
${ }^{14}$ Como afirma Meneses (2004, p. 54), a Entfremdung "[...] constitui um esvaziamento ou perda de essência em benefício de um ser-aí outro, alheio $($ fremd $)$, em que o sujeito não se reconhece, e que antes se lhe opốe como adverso"; é, portanto, "[...] uma situação donde não há retorno". Já na Entäusserung, “[...] temos aqui um 'fazer-se ser'. Em vez de esvaziamento, empobrecimento, temos uma força que faz o que é puramente interior exteriorizar-se, objetivar-se. E sobretudo, nessa objetivação, o sujeito se reconhece e retorna para si mesmo, conhecendo-se melhor do que antes se conhecia, num enriquecimento tanto no plano do conhecimento quanto da realidade".
} 
nessa experiência da consciência (i.é, fenomenologicamente, embora não lógico-conceitualmente, distinção esta que se justifica pelas diferenças de objeto dessas duas ciências filosóficas: enquanto uma tem seu objeto na consciência finita, outra o tem no pensamento em si e para si, lógico-real). Trata-se, antes, não de uma identidade imediata, porém, de uma unidade contraditória de exteriorização e alienação apresentada por Hegel (1992b, p. 35; 1970d, p. 360) nos seguintes termos:

[...] o mundo tem aqui a determinaçáo de ser algo exterior [Äusserliches], o negativo da consciência-de-si. Contudo, este mundo é essência espiritual, é em si a compenetração do ser e da individualidade. Seu ser-aí é a obra da consciência-de-si, mas é igualmente uma efetividade imediatamente presente, e estranha [fremde] a ela; tem um ser peculiar e a consciência-desi ali não se reconhece [sich nicht erkennt].

[...] essa efetividade exterior é seu [da autoconsciência] trabalho. [...] Adquire seu ser-aí [sua existência, Dasein] pela própria exteriorização [Entäusserung] e des-essenciamento [Entwesung] da consciência-de-si. [...] e contudo, essa dissoluçáo - essa sua essência negativa - é precisamente o Si: que é seu sujeito, seu agir e seu vir-a-ser. Ora, esse agir e vir-a-ser, mediante os quais a substância se torna efetiva, é a alienação da personalidade; com efeito, o Si vigente em si e para si, imediatamente, isto é, sem alienação, é um $[\mathrm{Si}] \mathrm{sem}$ substância [...] Sua substância é, pois, sua exteriorização [Entäusserung], e sua exteriorização é a substância - ou seja, as potências espirituais que se ordenam para [constituírem] um mundo e por isso se mantêm.

A substância, dessa maneira, é espirito, unidade consciente-de-si do Si e da essência; mas os dois têm também, um para o outro, o significado da alienação.

Poucas linhas depois, Hegel (1992b, p. 35; 1970d, p. 360) ressalta, ainda: “[...] graças a sua exteriorização [Entäusserung], a autoconsciência efetiva passa ao mundo efetivo”. É pela exteriorização, portanto, que a autoconsciência se efetiva num mundo efetivo. Que estas exteriorização e efetivação, justamente por constituírem um mundo efetivo, resultem em alienação, deve-se a que a efetividade exterior - nesse nível da experiência fenomenológica - é fixa, rígida, impenetrável à própria consciência, numa universalidade na qual a autoconsciência não se reconhece. Essa exteriorizaçáo, imposta numa relaçáo negativa para com a autoconsciência, resulta numa efetividade alienada sem a qual, contudo, nem o Si espiritual (o absoluto como sujeito) vem-aser sujeito de si nem a substância (o absoluto como substância) se efetiva como substância espiritual. A substância aí, cuja imediatidade retorna para a 
autoconsciência como alienação, é a exteriorização da mesma autoconsciência enquanto processo de constituição do mundo espiritual (substância), do qual o próprio espírito (forma do absoluto) é sujeito $(\mathrm{Si})$. Quando Hegel assevera que, "[...] sem alienação, o Si é um Si sem substância”, afirma justamente a tese especulativa de que esta saída de si do $\mathrm{Si}$, em direção a uma exterioridade que, sendo sua exterioridade, é, no entanto, dele alienada, constitui precisamente assim o processo pelo qual o $\mathrm{Si}$ espiritual se faz sujeito de si ao dar-se a si mesmo uma existência substancial. A tese, anunciada no Prefácio ao Sistema, de que o absoluto é, não apenas substância, mas também sujeito, exercita aqui toda sua valência; do ponto de vista da função sistemática da Fenomenologia do Espirito, esse movimento especulativo tem, pois, um significado mais geral, que se reapresenta igualmente nesse teor específico, que é a unidade sujeitoobjeto na unidade sujeito-substância no e pelo Si substancial espiritual. A consciência que realiza a experiência exercita aí (enquanto ser-aí do espírito que em verdade é) um movimento espiritual mais amplo, constitutivo da própria Bildung do espírito, ainda que, como autoconsciência ainda não-reconciliada no saber absoluto, não se reconheça na efetividade em que se exterioriza.

Ora, é justamente porque a autoconsciência experimenta sua exteriorização (e efetivação) como não reconhecimento e, em consequência, alienação, que essa mesma experiência se constitui em formação cultural (Bildung). Para a autoconsciência, não há outra via de formação que a exteriorização, enquanto radical saída de si, e a consequente efetivação, enquanto experiência com um mundo efetivo (substancial) relacionado com ela, no modo da alienaçáo, ao qual, por conseguinte, ela não reconhece como seu. É essa radicalidade da alienação, constitutiva da formação, que Hegel expressa no suficientemente eloquente termo "des-essenciamento" (Entwesung), um deixar de ser o que é, só possível numa radical saída de si que, para a autoconsciência, torne o Si alienado de si mesmo (o que ocorre, na exposição da Fenomenologia, quando a alienação chega à linguagem).

Em correspondência a essa cisão que há entre a autoconsciência e seu mundo efetivo, Hegel considera - nos termos próprios à exposição fenomenológica do espírito, isto é, como figuras da consciência - uma duplicação no interior da autoconsciência mesma: ela é consciência efetiva e é, em oposição e em consequência dessa exteriorização (efetivação), uma pura consciência. ${ }^{15}$ A pura consciência é uma duplicação da autoconsciência como

${ }^{15}$ Essa duplicação é o modo específico como se atualizam, nessa figura experiencial da consciência, os
momentos internos de saber e verdade, cuja dialética consiste na própria experiência fenomenológica. 
oposição à - e, portanto, em decorrência da - consciência efetiva $;{ }^{16}$ daí advém o mundo da pura consciência, "[...] oposto [entgegengesetze] àquela alienação, [e que] por isso mesmo não é livre dela, mas antes é somente a outra forma da alienação, que consiste precisamente em ter a consciência em dois mundos diversos e que abarca ambos" (HEGEL, 1992b, p. 38; 1970d, p. 363).

Essa passagem é particularmente importante, pois revela que, se à duplicação dos objetos do saber da consciência entre "poder de Estado" e "riqueza" se segue uma duplicação da consciência entre consciência efetiva (momento do saber) e consciência pura (momento da verdade), esses dois termos em que aquela se duplica são ambos os termos da alienação. Poder de Estado e riqueza são, nesse momento da exposição fenomenológica, as formas objetivas do mundo finito que constituem para a consciência efetiva a objetividade da experiência (seus objetos do saber), objetividade na qual ela não se reconhece e, por isso, se lhe apresenta como objetividade alienada. ${ }^{17}$ Nessa duplicação da consciência, a pura consciência se distingue de, se opóe à e se eleva sobre a consciência efetiva, justamente porque esta, em seu movimento de exteriorização e efetivação, constitui sua alienação; mas, para Hegel, a pura consciência é apenas “a outra forma de alienação”. Ora, a alienação emerge nesse ponto da experiência da consciência com o mundo do espírito finito, no qual ao desdobramento do objeto da consciência em riqueza e poder de Estado corresponde, no interior da consciência, a divisão entre os momentos de consciência efetiva (momento da consciência que se relaciona com a efetividade) e a pura consciência, que se opóe ao mundo efetivo. De acordo com Hegel, a pura consciência se apresenta como alienação justamente porque se lhe opóe na recusa da objetividade/efetividade: enquanto, para a consciência, em seu momento de verdade (nessa figura, a pura consciência), a efetividade na qual ela não se reconhece constitui sua alienação, à qual se opóe

A consciência efetiva é, assim, o momento exteriorizado e objetivado do saber; já a pura consciência, o momento autorreflexivo e autoconsciente da verdade.

${ }^{16}$ Como compreende a nota anterior, também aqui o momento de verdade (pura consciência) é o momento de verdade desse saber (consciência efetiva), repondo o mesmo movimento dialético entre saber e verdade que Hegel apresenta, na "Introdução" à Fenomenologia do Espírito, como a estrutura da totalidade da experiência, segundo a exigência de que a negatividade presente nessa experiência seja imanente à própria consciência que faz a experiência.

${ }^{17}$ Poder de Estado e riqueza não são, portanto, objetos de uma exposição em suas determinaçôes constitutivas, tal como encontramos nos Princípios da filosofia do direito, mas objetos do saber da consciência, cujo percurso fenomenológico é abordado na obra que estamos discutindo. Assim como o isto é o objeto da certeza sensível, a coisa o é da percepção etc., o Poder de Estado e a riqueza o são, nesse momento da exposição fenomenológica, da consciência efetiva em sua oposição intraconsciencial à pura consciência. 
nas formas da fé e do conceito, para nós (isto é, a consciência filosófica que expóe o percurso fenomenológico: Hegel), a pura consciência se inscreve nesse mesmo quadro de alienação, sendo outra forma desta, e justamente porque se opóe à alienação, opondo-se à efetividade.

Como recusa intraconsciencial da efetivação, da exteriorização, a consciência pura opóe-se ao mundo efetivo do poder de estado e da riqueza de dois modos: pela fé e pelo conceito. Fé não se refere aqui à religião, que, para Hegel, é sempre, em seu conceito, uma experiência afirmadora do mundo, mas, de fato, à negaçáo desse mundo em nome de um mundo outro. Do mesmo modo, conceito não se refere nesse momento da exposição fenomenológica ao pensamento conceitual, filosófico (especulativo), porém, à conceptualização abstrata, representativa, que se apresenta em concepçôes a-históricas e, portanto, dissolutoras da objetividade histórico-social, da objetividade em que se efetiva, de modo alienado, a exteriorização do espírito. Fé e conceito são, assim, momentos constitutivos da pura consciência que têm, em comum, uma relação antagonista com a consciência efetiva, enquanto esta é o saber do mundo efetivo do espírito; justamente assim, a pura consciência não reconhece este mundo de efetividade espiritual, ainda que ele seja, enquanto exteriorização, a efetivação da própria autoconsciência. É esse quadro contraditório no interior da própria (auto)consciência que constitui o mundo efetivo como mundo alienado em e para ela.

Neste passo da exposição hegeliana do percurso fenomenológico do espírito, as tendências à dissolução do efetivo exterior são tendências internas à autoconsciência que se instituem com base na e em oposição à alienação. Fé e conceito são, contudo, segundo julga o próprio Hegel (ou o "para nós"), dois modos alienados de oposição à alienação, pois pretendem abolir a alienação abolindo ou dissolvendo a efetividade de que aquela - para a consciência imersa na experiência fenomenológica - se constitui. Sem dúvida, fé e conceito são opostos, mas se constituem ambos com base numa mesma necessidade de negação abstrata do real. É importante notar que a exposição de Hegel é crítica dessas tendências dissolutoras da efetividade, as quais, no prosseguimento da experiência da consciência, se conduzem, na figura da Aufklärung, à liberdade absoluta e à consciência moral, duas posições abstratas da autoconsciência frente à efetividade espiritual. Não se trata aqui da Aufklärung histórica, porém, de uma figura da consciência que emerge, na experiência fenomenológica, da negação, que, na figura anterior, a pura consciência (verdade) opôs à consciência efetiva (saber). Ao conduzir-se, em sua unilateralidade e abstração, à dissolução do efetivo pela liberdade absoluta e a consciência moral, a figura da Aufklärung 
- enfatiza Hegel - completa, conclui, consuma, enfim, dá acabamento, ao processo de formaçáo cultural (Bildung) e, com ela, à alienaçáo (Entfremdung) que dela é constitutiva. Os termos com que Hegel (1992b, p. 37; 1970d, p. 362) anuncia essa passagem à figura da Aufklärung, nos parágrafos introdutórios da seção dedicada à formação cultural ("B. O espírito alienado de si mesmo. A formação cultural”), parecem suficientes para distinguir que a consciência filosófica que apresenta a experiência da consciência tem uma compreensão distinta da que tem a própria consciência experienciante:

[...] esses mundos espirituais, cujos momentos se afirmam todos como uma efetividade fixa e uma subsistência não-espiritual, vão dissolver-se na pura inteligência. Essa, como o Si que se apreende a si mesmo, consuma [completa, vollendet] a formação cultural [Bildung]: nada apreende senão o Si, e tudo apreende como o $\mathrm{Si}$, quer dizer, tudo conceitua; suprime toda a objetividade e transmuda todo o ser-em-si em ser-para-si. Voltada contra a fé, como reino da essência estranho e situado além, [ela] é o iluminismo [Aufklärung].

Para Hegel, a formação cultural se constitui justamente dessa experiência de cisão, des-essenciamento e alienação; no momento em que, na figura da Aufklärung, a alienação é suprimida, pois na liberdade absoluta e na consciência moral o é a própria objetividade, a Bildung se completa, ou o que é especulativamente o mesmo, se acaba. O lugar próprio à formação cultural é a exteriorização, a efetivação, que, na cisão e no não-reconhecimento de si da autoconsciência no mundo aí efetivado, se convertem em alienação. É esse quadro contraditório de exteriorização (Entäusserung) e alienação (Entfremdung) que constitui o próprio quadro possível da formação cultural, na medida em que esta mesma consiste necessariamente em uma perda radical e uma alteração não menos radical de si (des-essenciamento, Entwesung), que exigem, para o reencontro de si, a incorporação do que se lhe acrescentou na exteriorização vivida como alienação. ${ }^{18}$

\footnotetext{
${ }^{18}$ Não sendo o caso de apresentar um quadro completo dessa relaçấo entre Bildung e Entfremdung, no pensamento de Hegel, é possível, contudo, lembrar aqui como se dá essa relação alguns anos antes da escrita da Fenomenologia, justamente no ensaio sobre a Diferença entre os sistemas de Fichte e Schelling (1801). Nessa obra, Hegel refere-se não à Enfremdung, mas à Entzweiung: "Cisão [Entzweiung] é a fonte da necessidade da filosofia e, enquanto formação [Bildung] da época, o aspecto não-livre, dado da figura. $\mathrm{Na}$ formaçáo, aquilo que é manifestação do absoluto se isolou do absoluto e se fixou como algo autônomo". Alguns parágrafos adiante, afirma ainda: "Quanto mais avança a formação [Bildung], quanto mais variado se faz o desenvolvimento das externaçóes da vida [Äusserungen des Lebens], no qual pode entrelaçar-se a cisão [Entzweiung], maior chega a ser o poder desta, mais firme sua consagração climática, e os esforços da vida por gestar de novo sua própria harmonia devêm mais estranhos ao todo da formação e mais insignificantes" (HEGEL, 1990, p. 18; 1970b, p. 20).
} 
$\mathrm{Na}$ exposição acima, buscamos esclarecer a natureza das categorias de exteriorização, alienação e formação cultural, com base no lugar sistemático da Fenomenologia do Espirito (fundamentalmente, com a relação entre ela e a Ciência da Lógica, tal como pensada na primeira exposição do sistema de Hegel, entre 1807 e 1812), de modo que, em consequência, consideramos não ser possível uma identificação categorial direta entre a discussão de Hegel, no capítulo VI dessa obra, e as formas objetivas do espírito as quais serão objeto de exposição em outras ciências filosóficas constitutivas do sistema. Tendo em vista o objeto e o método expositivo da Fenomenologia do Espirito, a alienação se apresenta, nessa obra, como um fenômeno consciencial, de modo que é apenas nessa sua conformação que ela pode ser superada, pois todos os fenômenos de que trata a Fenomenologia do Espírito são conscienciais. A consciência é o próprio fenômeno-objeto dessa ciência filosófica (e da obra que a expõe). Igualmente, não é para Hegel, mas apenas para a própria consciência experienciante (na forma duplicada da pura consciência), que efetividade/ objetividade se identifica à alienação ou, ainda, para quem a alienação é a oposição da efetividade ao pensar abstrato. $\mathrm{Na}$ exposição de Hegel, essa relação negadora da objetividade é objeto de crítica, na forma da crítica à figura da consciência à qual dá o nome de Aufklärung, figura em que se completa a formação cultural. 
AQUINO, João Emiliano Fortaleza. Exteriorization, Alienation and Cultural Formation in Chapter VI of the Phenomenology of Spirit. Trans/Form/Ação, Marília, v. 37, n. 1, p. 131-130, Jan./Abr., 2014

\begin{abstract}
Our proposal is to consider the relationship between the systematic function of the Phenomenology of Spirit in Hegel's thought and the categories of externalization and alienation, according to the object and the expositive method related to this philosophical Science (and the work that exposes it). Thus, we present the hypothesis of a fundamental relationship between alienation and cultural formation in the chapter VI of the Phenomenology of Spirit. The demonstration that the exposition of this work does not treat of objects directly, but to the experience of consciousness against these objects, moves away from a reading that takes it as a thematization of objective social relations.
\end{abstract}

KEY-WORDS: Externalization. Alienation. Cultural Formation. Hegel.

\title{
REFERÊNCIAS
}

BARBOSA, A. M. Ciência e experiência: Um ensaio sobre a Fenomenologia do Espírito de Hegel. Porto Alegre: Edipucrs, 2010.

HEGEL, G. W. F. Enciclopédia das ciências filosóficas, I. Trad. br. Paulo Meneses. São Paulo: Loyola, 1995.

HEGEL, G. W. F. Fenomenologia do Espirito, I. Trad. br. Paulo Meneses. Petrópolis, RJ: Vozes, 1992a.

HEGEL, G. W. F. Fenomenologia do Espirito, II. Trad. br. Paulo Meneses. Petrópolis, RJ: Vozes, $1992 \mathrm{~b}$.

HEGEL, G. W. F. Diferencia entre los sistemas de filosofia de Fichte y Schelling. Trad. esp. Maria del Carmen Paredes Martín. Madrid: Tecnos, 1990.

HEGEL, G. W. F. Filosofía real. Trad. esp. José Maria Ripalda. Ciudad de México, Madrid, Buenos Aires: Fondo de Cultura Económica, 1984.

HEGEL, G. W. F. Die Wissenschaft der Logik. Werke in 20 Bänden, B. 5. Frankfurt am Main: Suhrkamp Verlag, 1970a.

HEGEL, G. W. F. Differenz des Fichteschen und Schellingschen Systems der Philosophie. Werke in 20 Bänden, B. 2. Frankfurt am Main: Suhrkamp, 1970 b.

HEGEL, G. W. F. Enzyklopädie der philosophischen Wissenschaften im Grundrisse. Werke in 20 Bänden, B. 8. Frankfurt am Main: Suhrkamp Verlag, 1970c.

HEGEL, G. W. F. Phänomenologie des Geites. Werke in 20 Bänden, B. 3. Frankfurt am Main: Suhrkamp Verlag, 1970d. 
HEGEL, G. W. F. A Ciência da Lógica. Prefácio. Trad. bras. Patrick de Oliveira Almeida, s/d (mimeo).

HYPPOLITE, J. Gênese e estrutura na Fenomenologia do Espírito de Hegel. Trad. bras. Sílvio Rosa Filho; Prefácio de Bento Prado Jr. 2. ed. São Paulo: Discurso Editorial, 1999.

LABARRIÈRRE, P-J. Les premiers combats de la reconnaissance. Maîtrise et servitude dans la "Phénoménologie de l'Esprit" de Hegel. Paris: Aubier, 1987.

LABARRIÈRE, P.-J. La Phénoménologie de l'Esprit de Hegel. Introduction à une lecture. Paris: Aubier-Montaigne, 1979.

MARX, K. Ökonomisch-philosophische Manuskripte aus dem Jahre 1844. In: MARX, K.; ENGELS, F. Werke. Ergänzungsband, 1. Teil. Berlin (DDR): Dietz, 1968.

MENESES, P. Abordagens hegelianas. Recife: FASA, 2004.

OLIVEIRA, M. A. A dialética do senhor e do escravo: a parábola do processo de humanização enquanto processo de libertação. In: Ética e sociabilidade. São Paulo: Loyola, 1993.

OLIVEIRA, M. A. Lógica transcendental e lógica especulativa. In: A filosofia na crise da modernidade. São Paulo: Loyola, 1989.

POEGGELER, O. Qu'est-ce qu'est la Phénoménologie de l'Esprit?. Études hégéliennes. Trad. fr. Marcel Régnier. Paris: Vrin, 1985.

SANTOS, J. H. dos. Trabalho e riqueza na Fenomenologia do Espirito de Hegel. São Paulo: Loyola, 1993.

VAZ. H. C. L. Escritos de filosofia IV. Introdução à Ética filosófica I. São Paulo: Loyola, 1999.

Submissão: 01/04/2013

Aceito em: 15/07/2013 